\title{
Finger millet bran supplementation alleviates obesity-induced oxidative stress, inflammation and gut microbial derangements in high-fat diet-fed mice
}

\author{
Nida Murtaza ${ }^{1}$, Ritesh K. Baboota ${ }^{1}$, Sneha Jagtap ${ }^{2}$, Dhirendra P. Singh ${ }^{1}$, Pragyanshu Khare ${ }^{1}$, \\ Siddhartha M. Sarma ${ }^{1}$, Koteswaraiah Podili ${ }^{3}$, Subramanian Alagesan ${ }^{4}$, T. S. Chandra ${ }^{5}$, K. K. Bhutani ${ }^{2}$, \\ Ravneet K. Boparai ${ }^{6}$, Mahendra Bishnoi ${ }^{1}$ and Kanthi Kiran Kondepudi ${ }^{1 *}$ \\ ${ }^{1}$ National Agri-Food Biotechnology Institute (NABI), C-127, Industrial Area, Phase 8, SAS Nagar, 160 071, Punjab, India \\ ${ }^{2}$ National Institute of Pharmaceutical Education and Research (NIPER), SAS Nagar, Punjab, India \\ ${ }^{3}$ Division of Biomedical Sciences, School of Biosciences and Technology, VIT University, Vellore, Tamil Nadu, India \\ ${ }^{4}$ Department of Millets, Tamil Nadu Agricultural University, Coimbatore, Tamil Nadu, India \\ ${ }^{5}$ Department of Biotechnology, Indian Institute of Technology Madras, Chennai, Tamil Nadu, India \\ ${ }^{6}$ Department of Biochemistry, Panjab University, Chandigarh, India
}

(Submitted 20 March 2014 - Final revision received 26 June 2014 - Accepted 11 July 2014 - First published online 19 September 2014)

\begin{abstract}
Several epidemiological studies have shown that the consumption of finger millet (FM) alleviates diabetes-related complications. In the present study, the effect of finger millet whole grain (FM-WG) and bran (FM-BR) supplementation was evaluated in high-fat diet-fed LACA mice for 12 weeks. Mice were divided into four groups: control group fed a normal diet (10\% fat as energy); a group fed a high-fat diet; a group fed the same high-fat diet supplemented with FM-BR; a group fed the same high-fat diet supplemented with FM-WG. The inclusion of FM-BR at $10 \%(\mathrm{w} / \mathrm{w})$ in a high-fat diet had more beneficial effects than that of FM-WG. FM-BR supplementation prevented body weight gain, improved lipid profile and anti-inflammatory status, alleviated oxidative stress, regulated the expression levels of several obesity-related genes, increased the abundance of beneficial gut bacteria (Lactobacillus, Bifidobacteria and Roseburia) and suppressed the abundance of Enterobacter in caecal contents $(P \leq 0.05)$. In conclusion, FM-BR supplementation could be an effective strategy for preventing high-fat diet-induced changes and developing FM-BR-enriched functional foods.
\end{abstract}

Key words: Obesity: Inflammation: Finger millet: Gut microflora: Prebiotic effects

Sedentary lifestyle and excess energy intake contribute to weight gain and obesity. Obesity causes low-grade inflammation, oxidative stress, altered adipose tissue secretome, and dysbiosis of beneficial gut microflora, which, in turn, contribute to the development of multiple chronic abnormalities such as atherosclerosis, diabetes and certain forms of cancers ${ }^{(1-3)}$. Anti-obesity medications have been shown to cause side effects. Therefore, exploration of alternative approaches is desirable, and that worth exploring is consumption of whole grains (WG), plant-derived dietary molecules including polyphenols, NSP (dietary fibres), prebiotics and probiotics ${ }^{(4)}$. Millets belong to the WG category and are rich in dietary fibres, proteins, energy, minerals, vitamins and antioxidants ${ }^{(5)}$. The consumption of various millets has been reported to protect from cancer, CVD and diabetes. The consumption of millets lowers cholesterol and fat absorption, delays gastric emptying and bulks the gastrointestinal contents ${ }^{(6,7)}$. The synergistic effect of bioactives in the WG contributes to more beneficial outcomes when compared with the effect of single bioactives ${ }^{(8)}$. Finger millet (FM), also known as ragi, is an important food crop for Africans and Indians. FM has been shown to alleviate diabetic complications ${ }^{(9)}$ and its health benefits can mainly be attributed to polyphenols ${ }^{(10)}$; carbohydrates; lysine-, threonine- and valine-rich proteins; crude fibres; and minerals ${ }^{(11)}$ Polyphenols in the seed coat of FM have been shown to exhibit antioxidant activity ${ }^{(12)}$ and in vitro antimicrobial activity ${ }^{(12)}$; inhibit rat intestinal and porcine pancreatic amylase ${ }^{(13)}$ and collagen glycation and crosslinking ${ }^{(14)}$; lower plasma glucose concentrations $^{(15,16)}$; improve dermal wound healing ${ }^{(17)}$; and exhibit hypoglycaemic, hypocholesterolaemic, nephroprotec-

Abbreviations: CE, cholesterol esters; $D L K 1$, delta-like 1 homolog; FASN, fatty acid synthase; FC, fold change; FM, finger millet; FM-BR, finger millet bran; FM-WG, finger millet whole grain; HFD, high-fat diet; HFD-BR, high-fat diet supplemented with finger millet bran; HFD-WG, high-fat diet supplemented with finger millet whole grain; $i N O S$, inducible nitric oxide synthase; LDL/VLDL-C, LDL/VLDL-cholesterol; $M I P-1 \alpha$, macrophage inflammatory protein-1 $\alpha$; ND, normal diet; PLIN1, perilipin 1; sWAT, subcutaneous white adipose tissue; TC, total cholesterol; vWAT, visceral white adipose tissue; WG, whole grains 
tive and anti-cataractogenic effects in streptozotocin-induced diabetic rats ${ }^{(18)}$. Due to its enormous health benefits, FM is considered to be a 'wonder grain' with superior nutritional qualities $^{(19)}$.

There are no reports on the effects of finger millet whole grain (FM-WG) or bran (FM-BR) supplementation on rodent models of high-fat diet-induced obesity and associated changes in gut microflora. The present study was designed to understand the role of FM supplementation in nutrigenomic changes associated with weight gain, serum biochemistry, oxidative stress, pro-inflammatory status and gut microbial derangements in high-fat diet-fed LACA mice.

\section{Materials and methods}

\section{Materials}

FM was procured from the Tamil Nadu Agricultural University, Coimbatore, Tamil Nadu. MTT (3-(4,5-dimethylthiazol-2-yl)2,5-diphenyltetrazolium bromide) was procured from HiMedia Leading BioSciences, India. All other chemicals used were of high quality and were purchased from local commercial sources.

\section{Finger millet bran and whole grain preparation}

The millet was washed, dried and ground to flour, and the bran was collected by repeatedly washing the whole flour to remove starch.

\section{Experimental animals and diets}

Swiss albino mice (LACA strain) (5-6 weeks old and 25 (SEM 3) g; 5-8 per group) were housed in the animal facility of the National Institute of Pharmaceutical Education and Research (NIPER), SAS Nagar, Punjab, India, under standard laboratory conditions (temperature $22 \pm 2^{\circ} \mathrm{C}$ and humidity $55 \pm 5 \%)$ and $12 \mathrm{~h}$ light $-12 \mathrm{~h}$ dark cycles and given free access to food and water. All experimental procedures were approved by the Institutional Animal Ethical Committee (IAEC), NIPER, and conducted according to the Committee for the Purpose of Control and Supervision on Experiments on Animals (CPCSEA) and Indian National Science Academy (INSA) guidelines on the use and care of experimental animals. After 1 week of acclimatisation, mice were randomly divided into four groups: control (Ctl) group fed a normal diet (ND; Research Diets, No. D12450B); a group fed a high-fat diet (HFD; Research Diets, No. D12451) deriving 45\% energy from fat; a group fed the same high-fat diet supplemented with finger millet bran (HFD-BR; 90\% HFD + 10\%(w/w) FM-BR); a group fed the same high-fat diet supplemented with finger millet whole grain (HFD-WG; 90\% HFD + 10\% (w/w) FM-WG). The composition of the HFD and ND is given in online supplementary Table S1. The experiment was conducted for 12 weeks. The food intake and body weights of mice were determined every alternate day.

\section{Oral glucose tolerance test}

An oral glucose tolerance test was performed in mice $1 \mathrm{~d}$ before killing. Mice were fasted overnight (12 h), and blood glucose concentrations ( $0 \mathrm{~min}$ ) of each mouse were measured after oral administration of $2 \mathrm{~g}$ glucose $/ \mathrm{kg}$ body weight. Blood glucose concentrations were measured at 15, 30, 60 and $90 \mathrm{~min}$ after glucose administration via tail snip method using the CareSens Blood Glucose Monitoring System (i-SENS, Inc.). The rate of glucose clearance was determined according to the method of Saucier et al. ${ }^{(20)}$.

\section{Tissue collection}

After the oral glucose tolerance test, mice were continued to be fed the respective diets for $24 \mathrm{~h}$ and then killed by cervical dislocation. Subcutaneous white adipose tissue (sWAT), visceral white adipose tissue (vWAT), brown adipose tissue, liver, skeletal muscle and pancreas were collected, snapfrozen and immediately stored at $-80^{\circ} \mathrm{C}$ until analysis. Caecal contents were collected immediately under aseptic conditions and stored at $-80^{\circ} \mathrm{C}$ for bacterial DNA isolation.

\section{Analysis of blood biochemical parameters}

Blood was allowed to settle and coagulate at room temperature for $20 \mathrm{~min}$ and then centrifuged at $4000 \mathrm{rpm}$ for $15 \mathrm{~min}$ to obtain serum. Serum total cholesterol (TC), free cholesterol, cholesterol ester (CE), NEFA, HDL-cholesterol, LDL/ VLDL-cholesterol (LDL/VLDL-C), ghrelin, and glucagon-like peptide-1 (Sigma Aldrich) and leptin, adiponectin and IL-1 $\beta$ (Invitrogen) concentrations were determined using ELISA kits according to the manufacturers' instructions.

\section{Biochemical estimations}

Multiple biochemical parameters were studied in sWAT, vWAT, liver, pancreas and skeletal muscle. A $10 \%(\mathrm{w} / \mathrm{v})$ homogenate of each tissue was prepared in $0.1 \mathrm{~m}-\mathrm{PBS}(\mathrm{pH} 7 \cdot 4)$ and centrifuged at $10000 \mathbf{g}$ for $15 \mathrm{~min}$, and the supernatant was aliquoted and used for the estimation of lipid peroxide, reduced glutathione, superoxide dismutase, catalase and nitrite levels $^{(21)}$. Mitochondrial fraction was isolated from the skeletal muscle and used for the spectrophotometric determination of complex I (NADH dehydrogenase), complex II (succinate dehydrogenase), complex III (MTT activity) and complex IV (cytochrome oxidase) activities ${ }^{(21)}$.

\section{RNA isolation and complementary DNA synthesis}

Total RNA was extracted from vWAT and brown adipose tissue using the TRIzol-based RiboPure RNA Extraction Kit (Invitrogen) according to the manufacturer's instructions. RNA was quantified using Infinite ${ }^{\circledR}$ M200 Pro NanoQuant (Tecan). The integrity of RNA samples was checked using $1.4 \%$ agarose gel. Intact and pure total RNA samples $(2.5 \mu \mathrm{g})$ were reverse-transcribed to complementary DNA using the 
RT First Strand Synthesis Kit (Qiagen) according to the manufacturer's instructions.

\section{Quantitative $P C R$}

The relative expression of different obesity-related genes in vWAT and thermogenic genes in brown adipose tissue was determined using a SYBR Green-based custom-designed mouse PCR array (CAPM11592C and CAPM11784) (SABiosciences, Qiagen) and that of $N F-\kappa B, M C P 1$ (monocyte chemoattractant protein 1), ADAM8 (A disintegrin and metalloproteinase domain 8 ), $M I P-1 \alpha$ (macrophage inflammatory protein-1 $\alpha$ ), CD68 (cluster of differentiation 68), F4/80 (epidermal growth factor-like module-containing mucin-like hormone receptor (EMR)1), TNF $\alpha$, IL-6, iNOS (inducible NO synthase), ADIPOQ (adiponectin), GLUT4 and ACC (acetyl-CoA carboxylase) in vWAT (list of primers used given in online supplementary Table S2) was determined by quantitative PCR (Applied Biosystems 7500 Fast Real-Time PCR machine). RT-PCR was carried out under the following conditions: $95^{\circ} \mathrm{C}$ for $10 \mathrm{~min}$, followed by forty cycles of $95^{\circ} \mathrm{C}$ and $60^{\circ} \mathrm{C}$ for $1 \mathrm{~min}$. Data were analysed using the $\Delta \Delta C_{\mathrm{t}}$
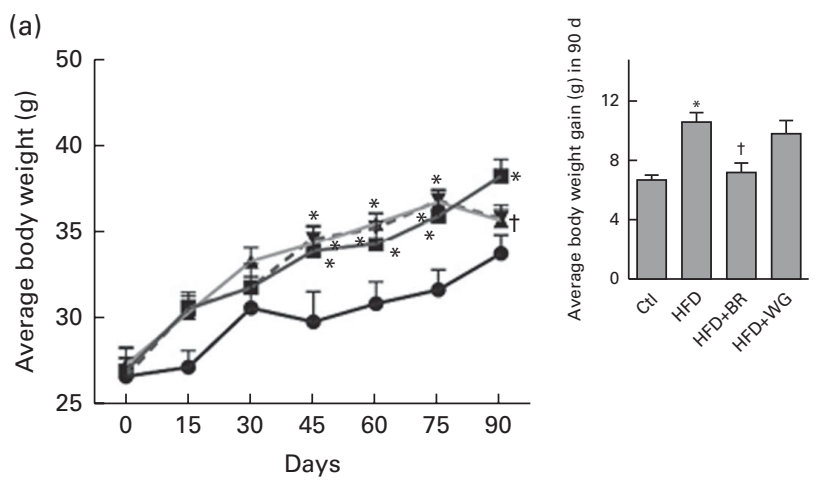

method, and values are expressed as fold change (FC) relative to the Ctl group.

\section{Microbial analysis of caecal contents}

DNA was isolated from $100 \mathrm{mg}$ of caecal contents of each mouse using the QIAamp ${ }^{\circledR}$ DNA Stool Mini Kit (Qiagen) according to the manufacturer's instructions. DNA was quantified using PRO NanoQuant (Tecan). Real-time quantification of Lactobacillus, Bifidobacteria, Roseburia, Akkermansia, Enterobacter and Bacteroides-Prevotella was performed using genus-specific primers and that of Bacteroidetes and Firmicutes using phylum-specific primers. Total bacterial DNA data were normalised, and the results are expressed as relative FC of bacterial DNA abundance compared with the Ctl group.

\section{Statistical analysis}

Values are given as means with their standard errors. Intergroup variation was analysed using ANOVA followed by Tukey's post hoc test using GraphPad Prism 5 software (GraphPad Software, Inc.). $P$ values $\leq 0.05$ were considered (b)
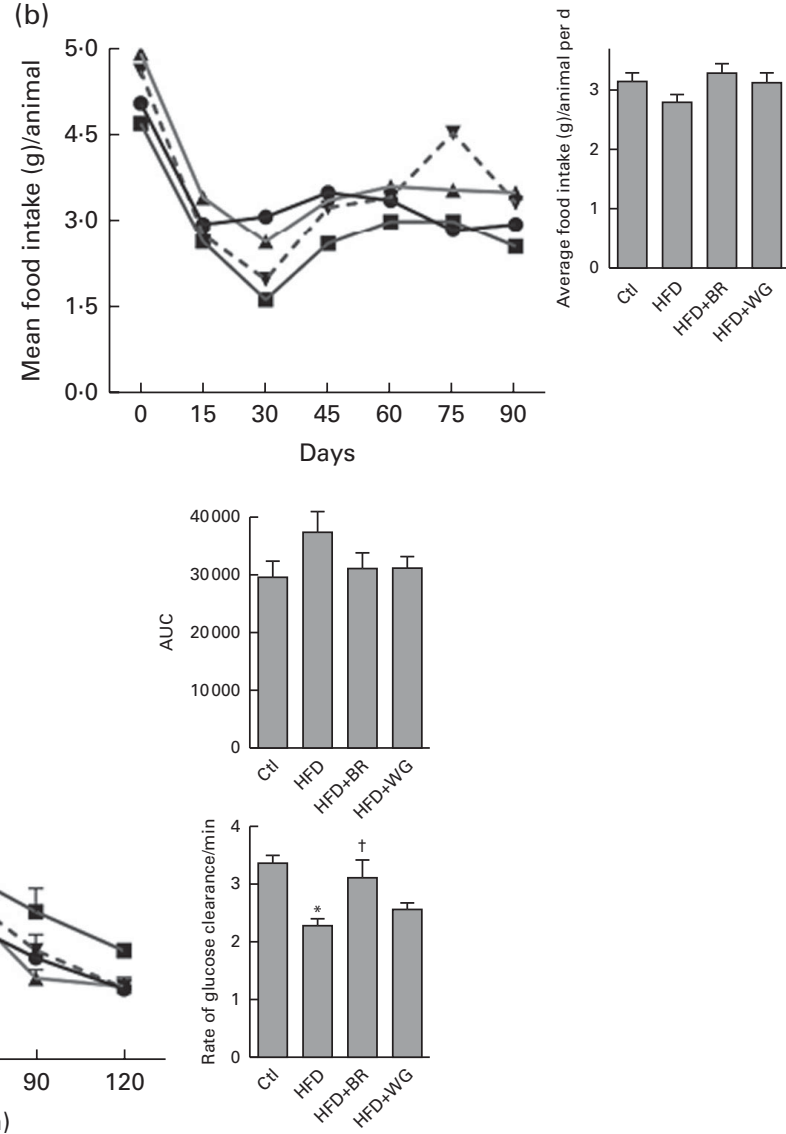

Fig. 1. Effect of finger millet bran- or finger millet whole grain-supplemented high-fat diet (HFD) on (a) body weight gain, (b) average food intake/animal and (c) oral glucose tolerance test results and glucose clearance in HFD-induced obese mice. Values are means, with their standard errors represented by vertical bars. * Mean value was significantly different from that of the control group $(P \leq 0.05$; one-way ANOVA followed by Tukey's post hoc test). $\dagger$ Mean value was

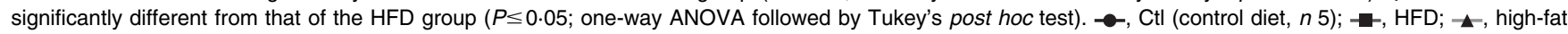
diet supplemented with finger millet bran (HFD-BR) and $=\mathbf{\nabla}$, high-fat diet supplemented with finger millet whole grain (HFD-WG) ( $n 6)$. To convert glucose in $\mathrm{mg} / \mathrm{dl}$ to $\mathrm{mmol} / \mathrm{l}$, multiply by 0.0555 . 
significant in all tests. Pearson's correlation analysis was performed between vWAT inflammatory markers $(N F-\kappa B, M C P 1$, $I L-6$ and $T N F \alpha$ ) and serum lipid profile (HDL-cholesterol, LDL-C and NEFA)

\section{Results}

Finger millet bran supplementation prevents body weight gain in high-fat diet-induced obese mice

HFD-fed mice exhibited a higher body weight gain at the end of 12 weeks when compared with ND-fed mice (Fig. 1(a)). HFD-BR-fed mice exhibited a decrease in body weight gain, while HFD-WG-fed mice exhibited no decrease in body weight gain when compared with HFD-fed mice (Fig. 1(a)). The food intake of all the experimental groups was similar (Fig. 1(b)).

\section{Finger millet bran supplementation increases glucose clearance}

No difference was observed in the AUC of the experimental groups in the oral glucose tolerance test (Fig. 1(c)). Glucose clearance was impaired in HFD-fed mice when compared with that in ND-fed mice (Fig. 1(c)), while it was enhanced in HFD-BR-fed mice when compared with that in HFD-fed or HFD-WG-fed mice. HFD-WG-fed mice exhibited no changes in glucose clearance when compared with HFD-fed mice (Fig. 1(c)).

\section{Finger millet bran or whole grain supplementation alters} the serum biochemical parameters

HFD-fed mice exhibited an increase in TC (40\%), CE (35\%), free cholesterol (74\%), NEFA (45.85\%), and LDL/VLDL-C (12.28\%) concentrations, but a decrease in HDL-cholesterol concentrations $(22.57 \%)$ when compared with ND-fed mice (Fig. 2). HFD-BR-fed mice exhibited neither an increase in TC, CE, free cholesterol, NEFA and LDL/VLDL-C concentrations nor a decrease in HDL-cholesterol concentrations when compared with HFD-fed mice (Fig. 2). HFD-WG-fed mice exhibited no increase in TC and CE concentrations or changes in free cholesterol, HDL-cholesterol, LDL/VLDL-C and NEFA concentrations when compared with HFD-fed mice (Fig. 2).

HFD-fed mice exhibited an increase in serum IL-1 $\beta$ (76.51\%), leptin (48.37\%) and ghrelin (76\%) concentrations when compared with ND-fed mice (Fig. 3). HFD-BR-fed and HFD-WG-fed mice exhibited no increase in these concentrations when compared with HFD-fed mice (Fig. 3).

\section{Finger millet bran or whole grain supplementation} alleviates oxidative stress in visceral white adipose tissue, subcutaneous white adipose tissue, liver and pancreas

HFD-fed mice exhibited an increase in lipid peroxide levels in vWAT, sWAT, liver and pancreas when compared with ND-fed mice (Fig. 4). The formation of lipid peroxide was prevented
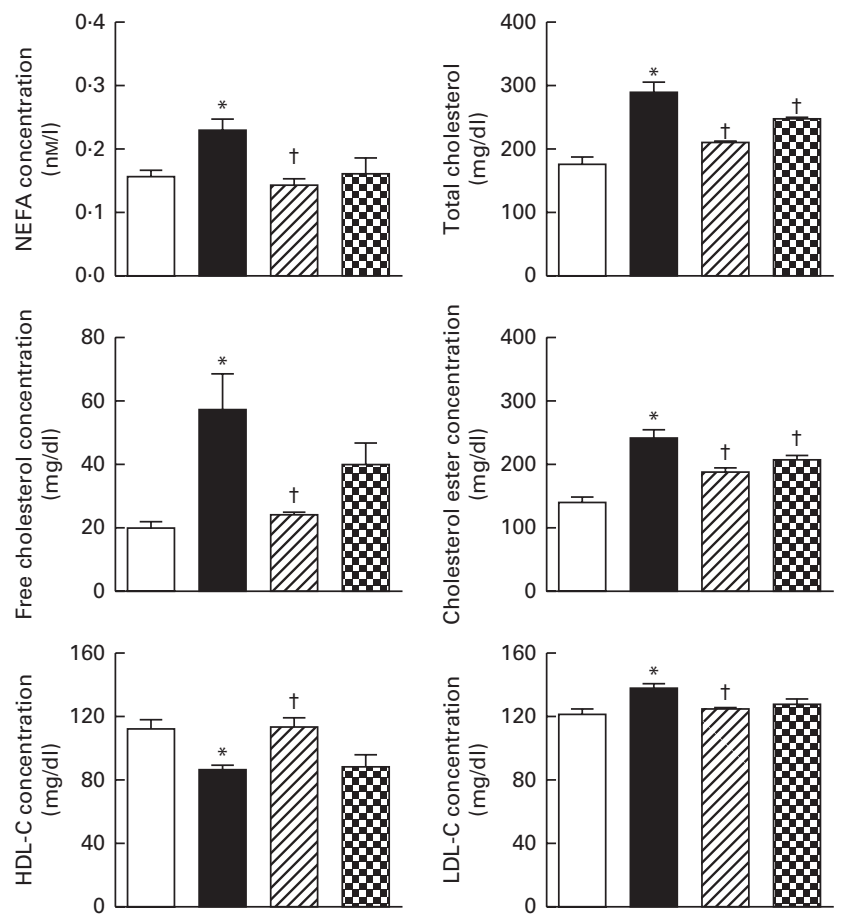

Fig. 2. Effect of finger millet bran- or finger millet whole grain-supplemented high-fat diet (HFD) on serum lipid profiles. Values are means, with their standard errors represented by vertical bars. * Mean value was significantly different from that of the control group $(P \leq 0.05$; one-way ANOVA followed by Tukey's test). † Mean value was significantly different from that of the HFD group ( $P \leq 0.05$; one-way ANOVA followed by Tukey's test). $\square$, Ctl (control diet); $\mathbf{}, \mathrm{HFD}$; $\oslash$, high-fat diet supplemented with finger millet bran (HFD-BR); ⿴囗十, high-fat diet supplemented with finger millet whole grain (HFD-WG). $n 3$ in all the groups. HDL-C, HDL-cholesterol; LDL-C, LDL-cholesterol. To convert cholesterol, HDL-C and LDL-C in $\mathrm{mg} / \mathrm{dl}$ to $\mathrm{mmol} / \mathrm{l}$, multiply by 0.0259 .

in all these tissues in HFD-BR-fed and HFD-WG-fed mice (Fig. 4)

HFD-fed mice exhibited an increase in nitrite levels in vWAT, but no changes in those in sWAT, liver and pancreas when compared with ND-fed mice and (Fig. 4). HFD-BR-fed and HFD-WG-fed mice exhibited a decrease in nitrite levels in vWAT and pancreas, but no changes in those in sWAT and liver when compared with HFD-fed mice (Fig. 4).

HFD-fed mice exhibited a decrease in reduced glutathione levels in vWAT, sWAT and liver when compared with ND-fed mice (Fig. 4). HFD-BR-fed and HFD-WG-fed mice exhibited an increase in reduced glutathione levels in these tissues when compared with HFD-fed mice (Fig. 4).

HFD-fed mice exhibited an increase in superoxide dismutase levels in vWAT when compared with ND-fed mice (Fig. 4). Superoxide dismutase levels were reduced in vWAT only in HFD-BR-fed and HFD-WG-fed mice, but remained unaltered in other tissues among the experimental groups (Fig. 4).

HFD-fed mice exhibited a decrease in catalase levels in vWAT and liver, but no changes in those in sWAT and pancreas when compared with ND-fed mice (Fig. 4). HFD-BR-fed mice exhibited an increase in catalase levels in vWAT and liver, but no changes in levels in sWAT and a decrease in those in 

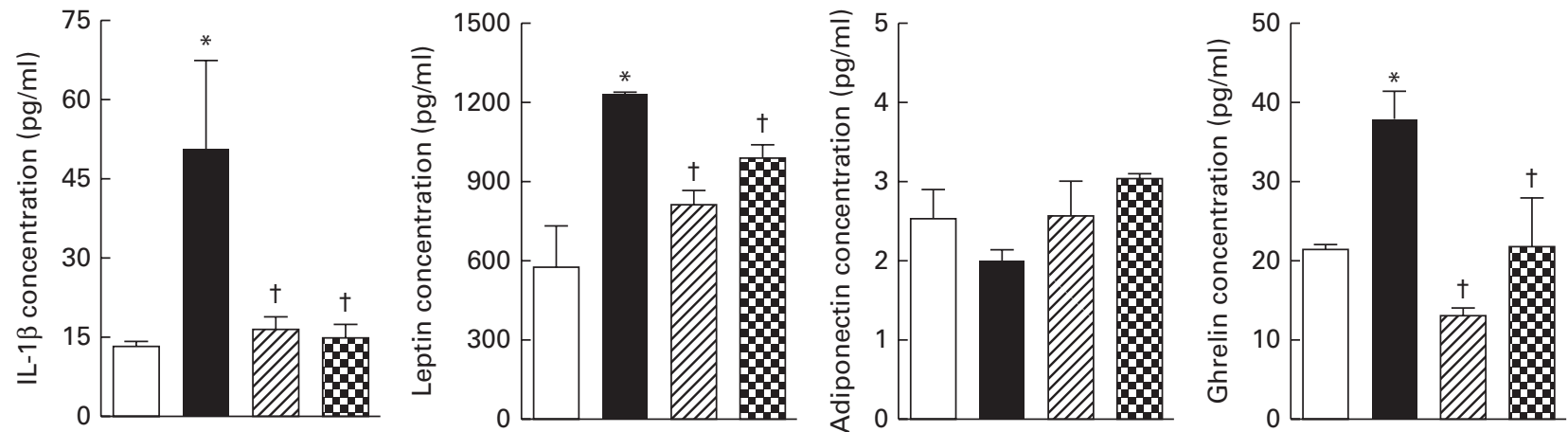

Fig. 3. Effect of finger millet bran- or finger millet whole grain-supplemented high-fat diet (HFD) on serum IL-1 $\beta$, leptin, adiponectin and ghrelin concentrations. Values are means, with their standard errors represented by vertical bars. * Mean value was significantly different from that of the control group ( $P \leq 0.05$; one-way ANOVA followed by Tukey's test). † Mean value was significantly different from that of the HFD group ( $P \leq 0.05$; one-way ANOVA followed by Tukey's test). $\square$, Ctl (control diet,

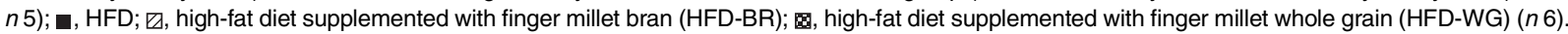

the pancreas when compared with HFD-fed mice (Fig. 4). HFD-WG-fed mice exhibited an increase in catalase levels in vWAT, liver and pancreas, but a decrease in those in sWAT when compared with HFD-fed mice (Fig. 4).

\section{Finger millet bran or whole grain supplementation} improves mitochondrial complex activities in the skeletal muscle

HFD-fed mice exhibited a decrease in mitochondrial complex I activity in the skeletal muscle, but no changes in complex II, III and IV activities when compared with ND-fed mice (Fig. 5). HFD-BR-fed mice exhibited enhanced mitochondrial complex I activity as well as complex II and III activities when compared with HFD-fed mice (Fig. 5). HFD-WG-fed mice exhibited an increase in mitochondrial complex I, II and III activities when compared with HFD-fed mice (Fig. 5). No changes were observed in mitochondrial complex IV activity among the experimental groups (Fig. 5).

Finger millet bran or whole grain supplementation alters the expression of obesity- and metabolism-related genes in visceral white adipose tissue

HFD-fed mice exhibited a decrease in the expression of $A D I P O Q \quad(\mathrm{FC}=-2 \cdot 10)$, but no changes in that of $D L K 1$ (delta-like 1 homolog), C/EBP $\alpha$ (CCAAT enhancer-binding protein- $\alpha$ ), PPAR $\gamma$ and PLIN1 (perilipin 1) when compared with ND-fed mice (Fig. 6(a)). HFD-BR-fed and HFD-WG-fed mice exhibited no changes in the expression of PPAR $\gamma$ and $C / E B P \alpha$ when compared with HFD-fed and ND-fed mice (Fig. 6(a)). HFD-BR-fed mice exhibited an increase in the expression of DLK1, PLIN1 and ADIPOQ (FC=3.00, 2.92 and $3 \cdot 36$, respectively) when compared with HFD-fed mice, while HFD-WG-fed mice exhibited an increase in the expression of DLK1 and adiponectin $(\mathrm{FC}=2 \cdot 72$ and $1 \cdot 17$, respectively), but no changes in that of PLIN1 when compared with HFD-fed mice (Fig. 6(a))

HFD-fed mice exhibited a decrease in the expression of metabolism-related genes such as ACC and GLUT4 $(\mathrm{FC}=-3.62$ and -1.70 , respectively), but a slightly enhanced expression of FASN (fatty acid synthase) when compared with ND-fed mice (Fig. 6(a)). However, HFD-BR-fed mice exhibited an increase in the expression of GLUT4 $(\mathrm{FC}=1 \cdot 18)$, but a decrease in the expression of $F A S N$ ( $\mathrm{FC}=-1.51)$ as well as no changes in that of ACC when compared with HFD-fed mice. HFD-WG-fed mice exhibited a decrease in the expression of $A C C$ and FASN ( $\mathrm{FC}=-3.07$ and -8.93 , respectively), but no changes in that of GLUT4 when compared with HFD-fed mice (Fig. 6(a)). There was no difference in the expression of GPD1 (glycerol3-phosphate dehydrogenase 1) in HFD-fed and HFD-BR-fed mice, while there was a decrease in the expression in HFD-WG-fed mice ( $\mathrm{FC}=-8.93)$. There was no difference in the expression of $A C O X 1$ (acyl Co-A oxidase1) among all the experimental groups.

HFD-fed mice exhibited an increase in the expression of $N F \kappa B, M I P-1 \alpha, A D A M 8, T N F \alpha, I L-6$ and $i N O S$ ( $\mathrm{FC}=1.54$, $1.45,2.42,6.27,1.65$ and 4.21 , respectively), but no changes in that of MCP1, F4/80 and CD68 when compared with ND-fed mice (Fig. 6(b)). The expression of all these proinflammatory genes was down-regulated in HFD-BR-fed mice when compared with that in HFD-fed mice (Fig. 6(b)). HFD-WG-fed mice exhibited a decrease in the expression of $N F \kappa B, M I P-1 \alpha, F 4 / 80, C D 68, T N F \alpha$ and $i N O S(\mathrm{FC}=0.77$, $-1.04,-4.81,-2 \cdot 21,5.65$ and 3.89 , respectively), but an increase in that of $I L-6$ and $A D A M 8$ ( $\mathrm{FC}=2 \cdot 17$ and $2 \cdot 91$ respectively) when compared with HFD-fed mice (Fig. 6(b)).

Pearson's correlation analysis between vWAT inflammatory markers (IL-6, TNF $\alpha, M C P 1$ and $N F \kappa B$ ) and serum lipid profile (HDL-cholesterol, LDL-C and NEFA) showed that the increase in serum HDL-cholesterol concentrations was positively correlated with the decrease in inflammatory gene levels in vWAT (HDL-cholesterol and $I L-6$ ( $r$ 0.688, $P=0.00653)$ and HDL-cholesterol and $N F \kappa B(r \quad 0.693$, $P=0.0063)$ ) and the increase in serum LDL-cholesterol concentrations was negatively correlated with the decrease in inflammatory gene levels in vWAT (LDL-cholesterol and $I L-6$ ( $r-0.563, P=0.022)$ and LDL-cholesterol and TNF $\alpha$ $(r-0.561, P=0.023)$ ). However, there was no correlation between serum NEFA concentrations and vWAT inflammatory gene levels. 

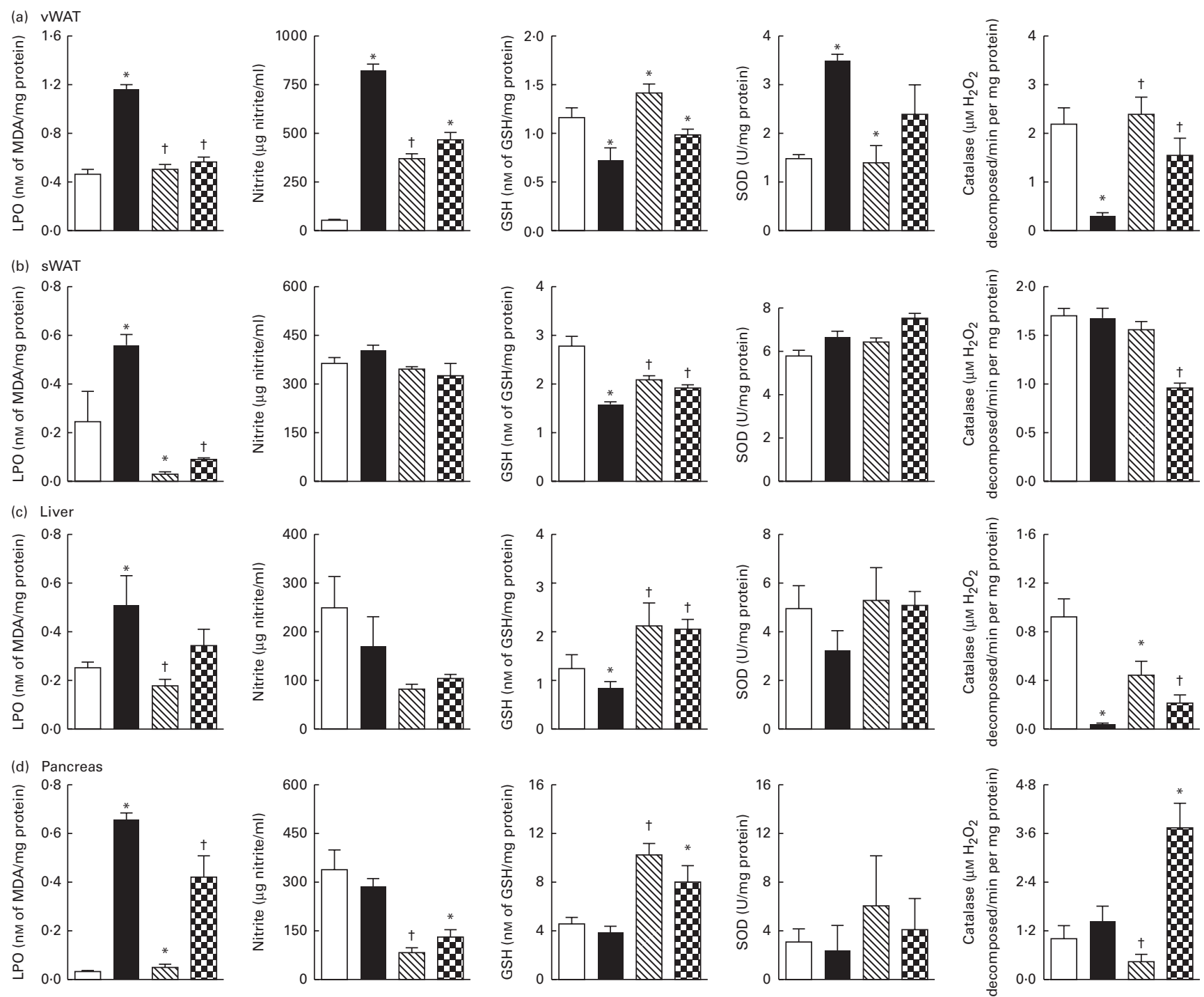

Fig. 4. Effect of finger millet bran- or finger millet whole grain-supplemented high-fat diet (HFD) on oxido-nitrosative stress in various tissues. Values are means, with their standard errors represented by vertical bars. * Mean value was significantly different from that of the control group $(P \leq 0.05$; one-way ANOVA followed by Tukey's test). † Mean value was significantly different from that of the HFD group ( $P \leq 0.05$; one-way ANOVA followed by Tukey's test). $\square$, Ctl (control diet, $n 5$ ); ఐ, HFD; $\square$, high-fat diet supplemented with finger millet bran (HFD-BR); 因, high-fat diet supplemented with finger millet whole grain (HFD-WG) ( $n$ 6). vWAT, visceral white adipose tissue; sWAT, subcutaneous white adipose tissue; LPO, lipid peroxides; MDA, malondialdehyde; GSH, reduced glutathione; SOD, superoxide dismutase.

Finger millet bran or whole grain supplementation has no effects on the expression of thermogenic genes in brown adipose tissue

HFD-fed mice exhibited an increase in the expression of thermogenic genes (PPAR $\alpha$, PRDM16 (PR domain containing 16), FOXC2 (Forkhead box C2), BDNF (brain-derived neurotrophic factor), ESSRA (oestrogen-related receptor- $\alpha$ ), CIDEA (cell death-inducing DNA fragmentation factor $\alpha$-like effector A), PGC1 $\alpha$ (PPAR- $\gamma$ co-activator-1 $\alpha$ ), SIRT1 (sirtuin 1) and $U C P 1$ (uncoupling protein 1)) when compared with ND-fed mice (online supplementary Fig. S1). However, the expression of these genes was not enhanced in HFD-BR-fed and HFD-WG-fed mice when compared with that in HFDfed mice (online supplementary Fig. S1), except for that of
AKT1 (v-akt murine thymoma viral oncogene homolog 1), which was higher in HFD-BR-fed and HFD-WG-fed mice, and that of PPAR $\alpha$, which was higher in HFD-WG-fed mice than in HFD-fed mice (online supplementary Fig. S1).

\section{Finger millet bran or whole grain supplementation beneficially manipulates selected gut microbial groups}

HFD-fed mice exhibited a decrease in the abundance of beneficial gut microbial groups such as Lactobacillus, Bifidobacteria, Roseburia, Akkermansia, Bacteroidetes and Bacteroides-Prevotella, but an increase in the abundance of pathogenesis-related Enterobacter and Firmicutes when compared with ND-fed mice (Fig. 7). 


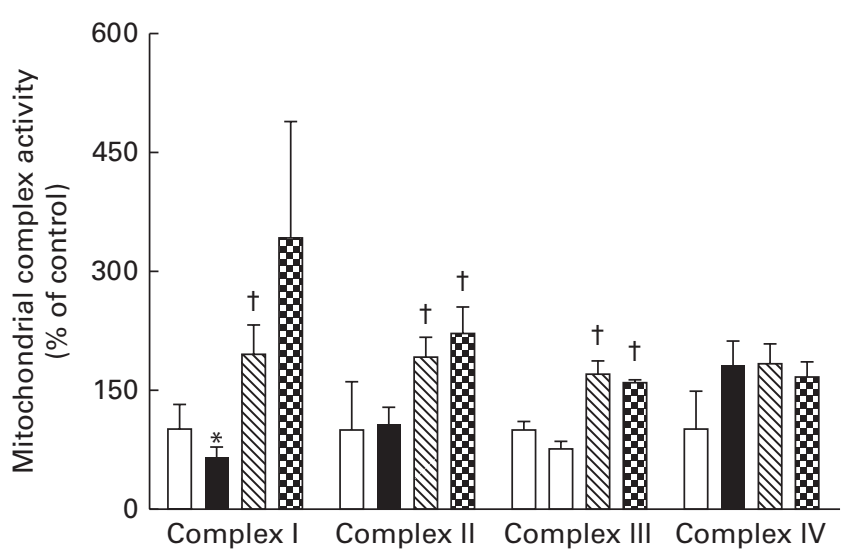

Fig. 5. Effect of finger millet bran- or finger millet whole grain-supplemented high-fat diet (HFD) on mitochondrial complex activities in the skeletal muscle. Values are means, with their standard errors represented by vertical bars. * Mean value was significantly different from that of the control group ( $P \leq 0.05$; one-way ANOVA followed by Tukey's test). † Mean value was significantly different from that of the HFD group $(P \leq 0.05$; one-way ANOVA followed by Tukey's test). $\square$, Ctl (control diet, $n$ 5); $\square$, HFD; $\square$, high-fat diet supplemented with finger millet bran (HFD-BR); $\$$, high-fat diet supplemented with finger millet whole grain (HFD-WG) $(n 6)$.

HFD-BR-fed mice exhibited an increase in the abundance of Lactobacillus when compared with HFD-fed mice, but the abundance was lower than that in ND-fed mice, while HFD-WG-fed mice exhibited an increase in the abundance of Lactobacillus when compared with HFD-fed, ND-fed and HFD-BR-fed mice (Fig. 7). The abundance of bifidobacteria and Roseburia was enhanced in HFD-BR-fed and HFD-WGfed mice when compared with that in HFD-fed and ND-fed mice (Fig. 7). However, the magnitude of the increase in the abundance of Roseburia in HFD-WG-fed mice was lower than that in HFD-BR-fed mice (Fig. 7). HFD-BR-fed and HFD-WG-fed mice exhibited no decrease in the abundance of Akkermansia and Bacteroidetes when compared with HFD-fed mice. However, their abundance was lower than that in ND-fed mice (Fig. 7). The abundance of BacteroidesPrevotella in HFD-BR-fed mice was restored to the levels observed in ND-fed mice when compared with that in HFD-fed and HFD-WG-fed mice (Fig. 7). HFD-BR-fed mice exhibited a decrease in the abundance of Enterobacter when compared with HFD-fed and ND-fed mice. Although HFD-WG-fed mice exhibited a decrease in the abundance of Enterobacter when compared with HFD mice, the magnitude of decrease was not high when compared with that in ND-fed mice (Fig. 7). HFD-BR fed mice exhibited a slight decrease in the abundance of Firmicutes. However, an increasing trend was observed in the abundance of Firmicutes in HFD-fed and HFD-WG-fed mice when compared with that in ND-fed mice (Fig. 7)

\section{Discussion}

The consumption of FM has been shown to have several health-beneficial effects ${ }^{(22)}$. However, the association between FM consumption and diet-induced obesity and related changes has not been investigated. In the present study, we showed that FM-BR and FM-WG CO-administered with HFD alleviated HFD-induced changes in mice. HFD-BR feeding prevented body weight gain relative to HFD or HFD-WG feeding. The absence of weight reduction in HFD-WG-fed mice might be due to high starch content with 70-80\% amylopectin in $\mathrm{FM}-\mathrm{WG}^{(23)}$. This finding emphasises that the consumption of WG low in glycaemic index or diets enriched with $\mathrm{BR}$ is more beneficial for preventing weight gain.

HFD-BR feeding counteracted the increase in serum TC, CE, NEFA and LDL/VLDL-C concentrations caused by HFD. Although there was no difference in weight gain between HFD-fed and HFD-WG-fed mice, the latter group exhibited a decrease in TC and CE concentrations. The hypocholesterolaemic effect of FM seed-coat matter has been observed in streptozotocin-induced diabetic rats ${ }^{(18)}$ and that of FM whole meal $^{(24)}$ as well as FM and kodo millet in alloxan-induced diabetic rats ${ }^{(16)}$. Chronic obesity leads to oxidative stress due to the formation of reactive oxygen species ${ }^{(25)}$. HFD-BR or HFD-WG feeding attenuated the effects of some of the parameters associated with oxidative stress induced by HFD feeding in vWAT, sWAT, liver and pancreas. This effect can be attributed to phenolic antioxidants, as has been reported in diabetic rodent models ${ }^{(18,26)}$, and dietary fibres. High leptin concentrations in obese animals and humans have been reported to be associated with leptin resistance ${ }^{(27)}$. The HFD-induced increase in leptin concentrations decreased upon HFD-BR or HFD-WG feeding.

HFD-BR or HFD-WG feeding reduced IL- $1 \beta$ concentrations to levels similar to those observed in ND-fed mice. Dietary interventions with FM, and more particularly with FM-BR, can be expected to not only help in the prevention of adipose tissue inflammation but also help in the prevention of ectopic fat deposition through reduction of IL-1 $\beta$ concentrations and adipose tissue inflammation by improving 'fat-liver cross talk ${ }^{,(28)}$. The expression of $N F \kappa B, M I P-1 \alpha, T N F \alpha$, iNOS, $A D A M 8$ and $I L-6$ in vWAT was high in HFD-fed mice as reported in the literature ${ }^{(29-33)}$. TNF $\alpha$ and $I L-6$ increase lipolysis and cause an increase in the concentrations of serum NEFA associated with obesity ${ }^{(34,35)}$, whereas $i N O S$ and $T N F \alpha$ cause obesity-induced insulin resistance in mice ${ }^{(30,36)}$. HFDBR feeding decreased the expression of all genes involved in inflammation, while HFD-WG feeding decreased the expression of $N F \kappa B, M I P-1 \alpha, F 4 / 80, C D 68$ and $T N F \alpha$ and slightly increased that of $I L-6$ when compared with HFD feeding. $I L-6$ has been shown to have dual functions, i.e. pro-inflammatory and anti-inflammatory, and to also inhibit lipid synthesis and promote lipid hydrolysis ${ }^{(37)}$. Furthermore, mice lacking $I L-6$ have been shown to revert from the obese state upon treatment with $I L-\sigma^{(37)}$. It is likely that $I L-6$ in the FM-WG group might have exerted an anti-obesity effect through the suppression of lipid synthesis or enhancement of lipid hydrolysis, as evidenced by a decrease in $F A S N$ expression and a slight increase in $A C O X 1$ expression in these mice. The results of the present study are in contrast to the those of the study carried out by Lee $e t a l{ }^{(5)}$, where no reduction in inflammation was observed when whole fox tail millet WG was co-administered with HFD. 

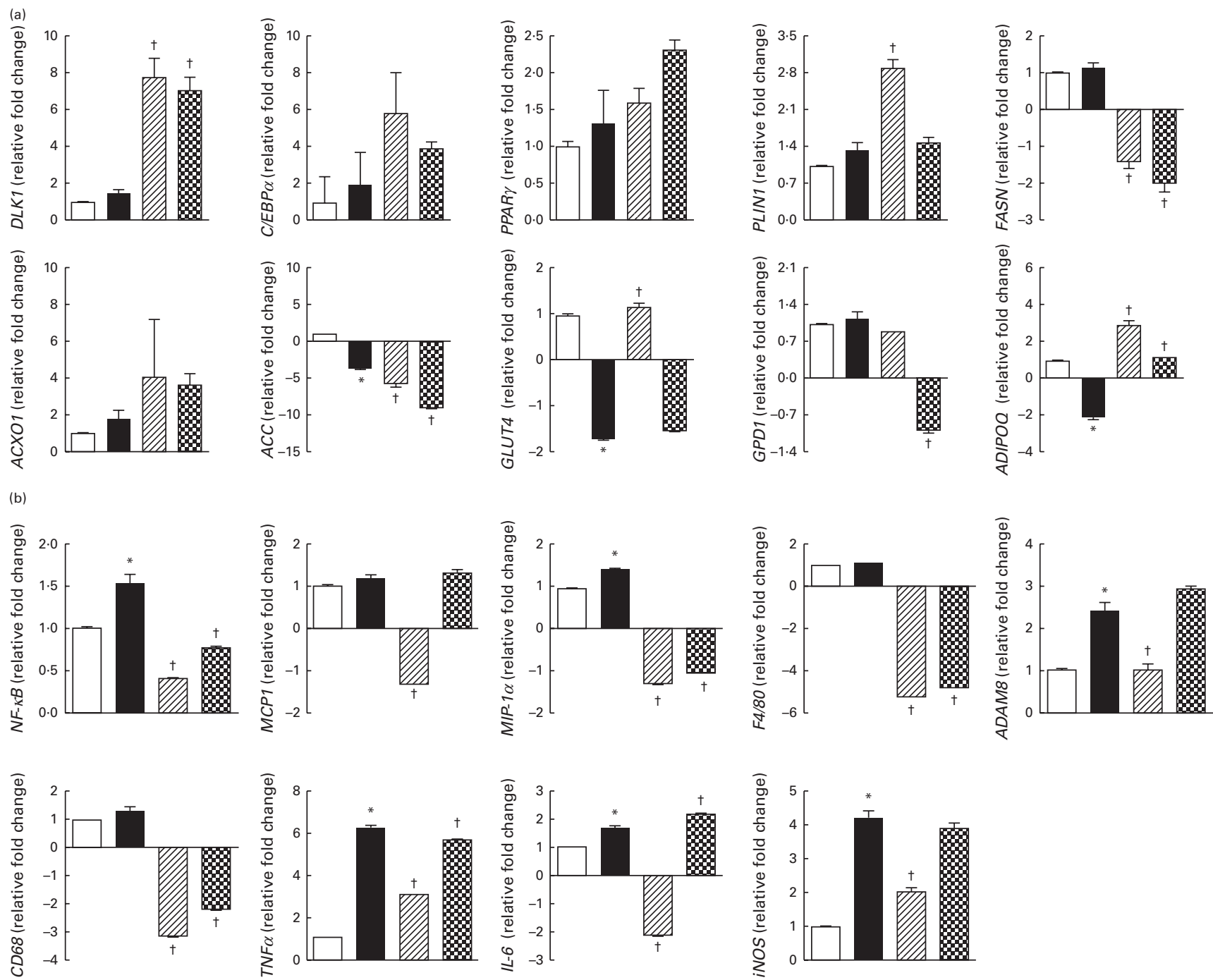

Fig. 6. Effect of finger millet bran- or finger millet whole grain-supplemented high-fat diet (HFD) on the expression of (a) obesity- and metabolism-related genes in visceral white adipose tissue (vWAT) and (b) inflammatory genes in vWAT. Values are means, with their standard errors represented by vertical bars. ${ }^{*}$ Mean value was significantly different from that of the control group $(P \leq 0.05$; one-way ANOVA followed by Tukey's test). $\dagger$ Mean value was significantly different from that of the HFD group ( $P \leq 0.05$; one-way ANOVA followed by Tukey's test). $\square$, Ctl (control diet, $n 5$ ); $\mathbf{n}, \mathrm{HFD} ; \square$, high-fat diet supplemented with finger millet bran

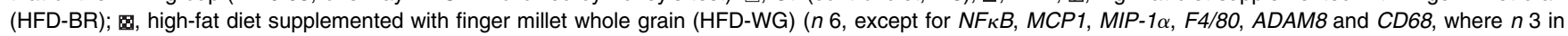
all the groups). Description of gene symbols is given in the 'Materials and methods' section.

The expression of DLK1 or Pref1 (preadipocyte marker 1) was enhanced in HFD-BR/HFD-WG-fed mice when compared with that in HFD-fed and ND-fed mice. $D L K 1$ is a preadipocyte marker exhibiting a lower expression in adipocytes ${ }^{(38)}$. Recently, DLK1 has been shown to induce Sox9 (sex-determining region-box 9) and promote chondrogenic induction of mesenchymal cells, but inhibit their differentiation into adipocytes as well as osteoblasts and chondrocytes ${ }^{(38,39)}$. Higher levels of DLK1 expression upon HFD-BR or HFD-WG feeding might inhibit the formation of new adipocytes from existing preadipocytes in vWAT. HFD-BR/HFD-WG feeding enhanced the expression of PLIN1 or PeriA, which has been shown to be highly expressed in adipocytes and protect unilocular lipid droplets from hydrolysis and contribute to obesity ${ }^{(40)}$. In a recent study, adipocyte-specific overexpression of PLIN1/PeriA has been shown to decrease diet-induced obesity by reducing lipid droplet size and fat-specific protein 27 (FSP27) expression; improving insulin sensitivity ${ }^{(41)}$; increasing fatty acid $\beta$-oxidation and heat production; and decreasing the expression of lipogenic genes ${ }^{(41)}$. In the present study, the expression of FASN was reduced and that of $A C O X 1$ was slightly enhanced in mice that were fed HFD-BR or HFDWG, respectively. FM-BR might have promoted fatty acid oxidation and decreased lipid synthesis in vWAT by increasing the expression of PLIN 1 and ACOX1 and decreasing that of FASN.

The expression of GLUT4 has been shown to decrease in rodent models of insulin deficiency ${ }^{(42,43)}$ and in adipose tissue of obese or type 2 diabetic humans, linking obesity to insulin resistance and implicating it to be a major risk factor for CVD and type 2 diabetes. HFD-BR feeding enhanced the expression of GLUT4 in VWAT, indicating that FM-BR 

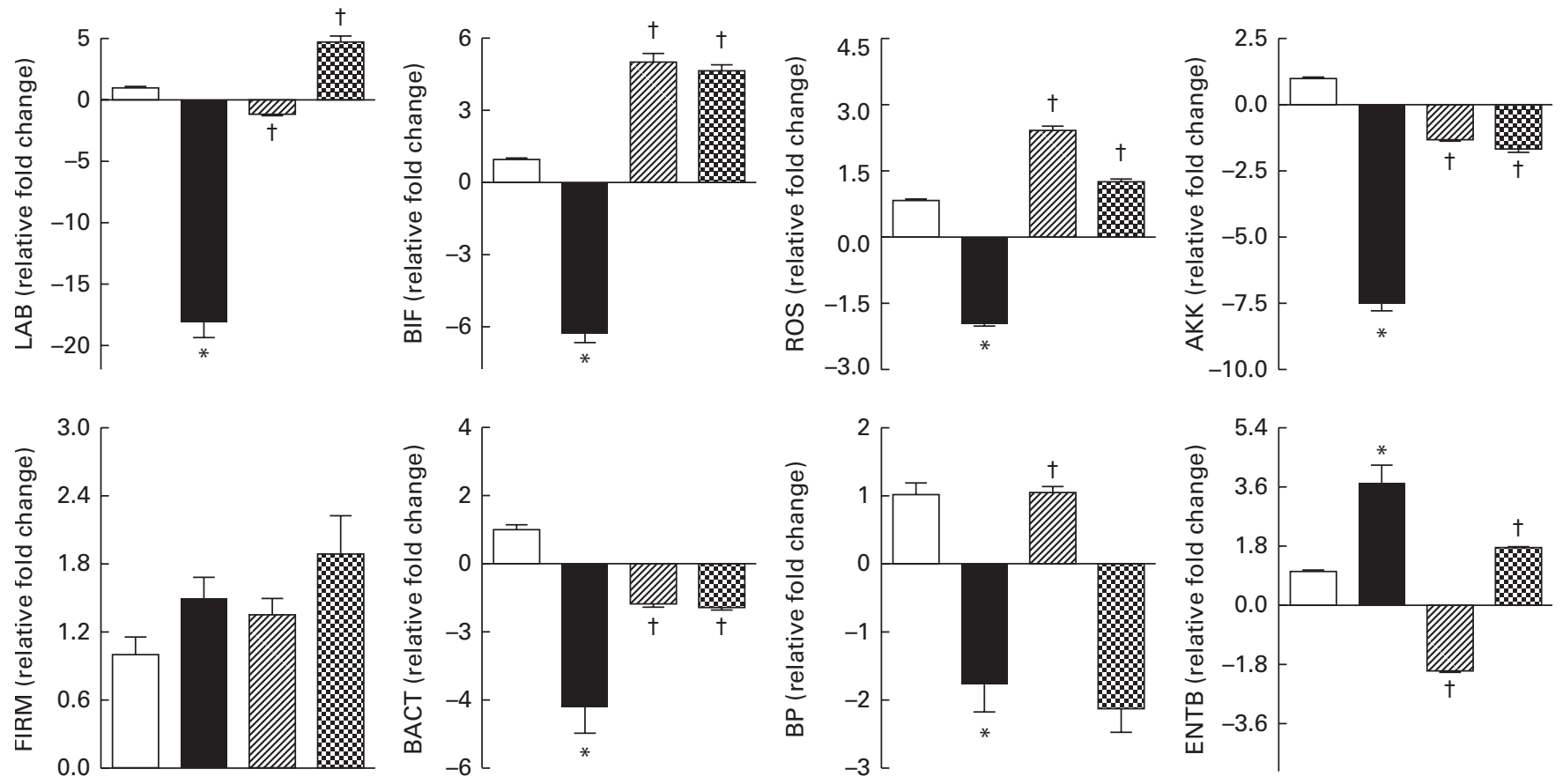

Fig. 7. Effect of finger millet bran- or finger millet whole grain-supplemented high-fat diet (HFD) on relative bacterial abundance in caecum. Values are means, with their standard errors represented by vertical bars. ${ }^{*}$ Mean value was significantly different from that of the control group $(P \leq 0.05$; one-way ANOVA followed by Tukey's test). † Mean value was significantly different from that of the HFD group $(P \leq 0.05$; one-way ANOVA followed by Tukey's test). $\square$, Ct

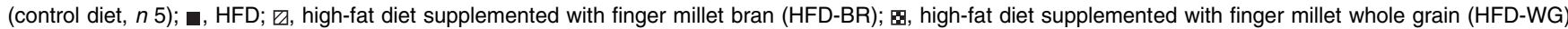
( $n$ 6). LAB, Lactobacillus; BIF, Bifidobacteria; ROS, Roseburia; AKK, Akkermansia; FIRM, Firmicutes; BACT, Bacteroidetes; BP, Bacteroides-Prevotella; ENTB, Enterobacter.

consumption might help to alleviate obesity-induced insulin resistance. However, adipose tissue only accounts for $10 \%$ of the insulin-mediated whole-body glucose uptake as suggested by other researchers ${ }^{(44,45)}$

Gut microflora has been recognised as a 'microbial organ' and is known for its remarkable metabolic and gut barrier function in humans ${ }^{(46)}$. Dysbiosis of gut microflora has been implicated in many infectious diseases, immune disorders and recently obesity ${ }^{(47)}$. Decreased abundance of Lactobacillus, Bifidobacteria, Roseburia, Akkermansia, and Bacteroidetes and increased abundance of Firmicutes and Gram-negative pathogens, especially Enterobacteriaceae members, in the gut of obese individuals have been reported $^{(48)}$. Enterobacter cloaca B29 has been shown to contribute to the development of obesity through altered gut barrier function due to lipopolysaccharides ${ }^{(49,50)}$, leading to low-grade inflammation and metabolic endotoxaemia ${ }^{(48)}$. In the present study, HFD feeding was found to cause a decrease in the abundance of Lactobacillus, Bifidobacteria, Roseburia, Bacteroidetes, Akkermansia and Bacteroides-Prevotella and an increase in that of Enterobacter. HFD-BR/HFD-WG feeding reversed the microbial derangements and exerted a 'prebiotic effect', i.e. increased the abundance of Lactobacillus, Bifidobacteria, Roseburia, Bacteroidetes and Bacteroides-Prevotella. The bifidogenic effect exhibited by oligofructose or wheat arabinoxylans has been reported to be accompanied by a decrease in the gene expression and activity of fatty acid synthase (FAS) in the adipose tissue ${ }^{(49,51)}$. In the present study, a similar bifidogenic effect and a decreased expression of FAS gene were observed in HFD-BR/HFD-WG-fed mice.

Roseburia spp. is an important butyrate-producing bacterium in the gut ${ }^{(52)}$. HFD-BR/HFD-WG feeding increased its abundance when compared with HFD or ND feeding. Roseburia might have stimulated butyrate-dependent anti-obesity effect ${ }^{(53)}$ or plausible conjugated-linoleic acid formation $^{(54)}$.

HFD-BR/HFD-WG feeding lowered the abundance of Enterobacter. As a consequence, lipopolysaccharide translocation might have decreased and gut barrier function improved, an important physiological consequence of gut microbial alteration, in HFD-BR-fed mice. The decreased $T N F \alpha$ and $I L-6$ expression in vWAT and circulatory IL- $1 \beta$ concentrations in HFD-BR-fed mice support our hypothesis. Even though the abundance of Enterobacter decreased in HFD-WG-fed mice, no reduction in $I L-6$ expression in vWAT was observed, despite decreased serum IL-1 $\beta$ concentrations.

The present study provides insights into the anti-obesity action of FM-BR, which is mediated via reduction of oxidative stress and inflammation, improvement in lipid profile, transcriptional changes in vWAT, and beneficial manipulation of gut microbial population (Fig. 8).

\section{Conclusion}

The results of the present study show that the inclusion of FM-BR at $10 \%(\mathrm{w} / \mathrm{w})$ in a HFD has more beneficial effects than that of WG. Therefore, FM-BR can be used as a nutra- 


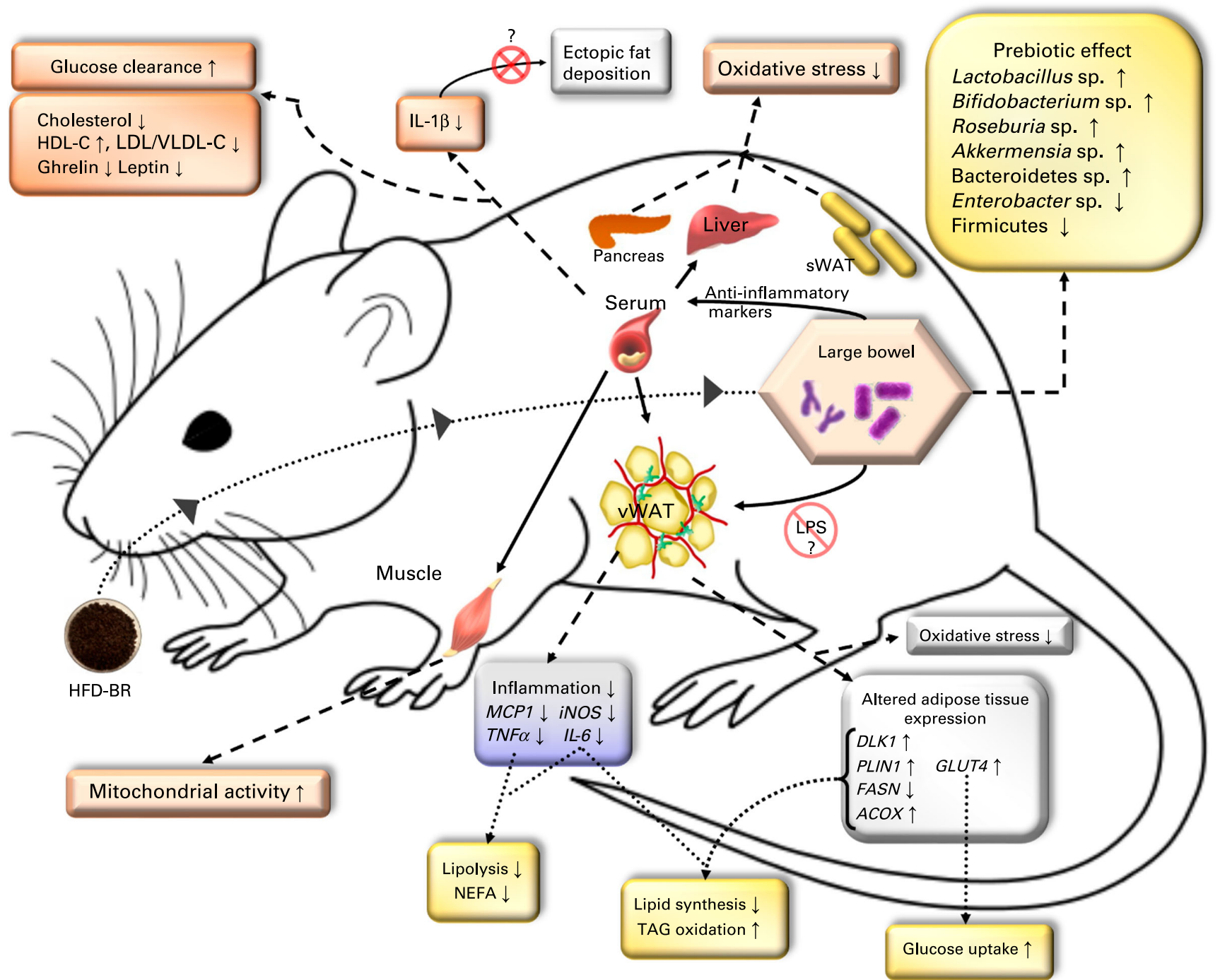

Fig. 8. Schematic diagram depicting the possible mode of action of finger millet bran supplementation in high-fat diet-fed mice. HFD-BR (high-fat diet supplemented with finger millet bran) feeding prevented an increase in serum lipid concentrations, increased glucose clearance, decreased oxidative stress in visceral white adipose tissue (vWAT), subcutaneous white adipose tissue (sWAT), liver, and pancreas, improved mitochondrial complex activities in the skeletal muscle, decreased the expression of adipogenesis-related gene (DLK1, PLIN1, FASN and GLUT4), decreased the expression of inflammation-related genes in vWAT ( $T N F \alpha, I L-6, M C P 1$ and $i N O S$ ), decreased the circulating concentrations of IL-1 $\beta$, ghrelin and leptin, and beneficially manipulated gut microflora (exhibiting prebiotic effect). Reduced IL-1 $\beta$ concentrations might prevent ectopic fat deposition. Beneficial gut microflora might enhance the gut barrier function and may prevent lipopolysaccharide (LPS) translocation into the circulation. HDL-C, HDL-cholesterol; LDL/VLDL-C, LDL/VLDL-cholesterol. Description of gene symbols is given in the 'Materials and methods' and 'Results' sections. A colour version of this figure can be found online at http://www.journals.cambridge.org/bjn

ceutical ingredient for the development of functionally enriched food products for the management of obesity and associated metabolic complications.

\section{Supplementary material}

To view supplementary material for this article, please visit http://dx.doi.org/10.1017/S0007114514002396

\section{Acknowledgements}

The authors thank the National Agri-Food Biotechnology Institute for providing infrastructure and fellowship to N. M.

The present study received financial support from the Department of Biotechnology (grant no. BT/PR6273/FNS/20/
622/2012) and the Department of Science and Technology (grant no. SB/FT/LS-224/2012), Government of India.

The authors' contributions are as follows: N. M. performed the animal studies and gene expression studies and wrote the manuscript; R. K. Baboota assisted in the gene expression studies and manuscript editing; S. J. and P. Khare performed the animal studies; D. P. S. performed the antioxidant assays; P. Koteswaraiah and T. S. C. contributed to the design of the antioxidant assays and manuscript editing; P. Khare and S. M. S. performed ELISA; N. M. and K. K. K. contributed to the gut microbial analysis and interpretation of the data; $\mathrm{S}$. A. provided the millet variety and contributed to manuscript writing; R. K. Boparai, M. B. and K. K. K. contributed to animal dissections; K. K. K., M. B. and K. K. B. contributed to the design of the experiments, analysed and interpreted the 
data, and drafted the manuscript. All authors read and approved the manuscript.

None of the authors has any conflicts of interest to declare.

\section{References}

1. Hubert HB, Feinleib M, McNamara PM, et al. (1983) Obesity as an independent risk factor for cardiovascular disease: a 26-year follow-up of participants in the Framingham Heart Study. Circulation 67, 968-977.

2. Kurth T, Gaziano JM, Berger K, et al. (2002) Body mass index and the risk of stroke in men. Arch Intern Med 162, $2557-2562$.

3. Calle EE, Rodriguez C, Walker-Thurmond K, et al. (2003) Overweight, obesity, and mortality from cancer in a prospectively studied cohort of U.S. adults. $N$ Engl J Med 348, $1625-1638$.

4. Baboota RK, Bishnoi M, Ambalam P, et al. (2013) Functional food ingredients for the management of obesity and associated co-morbidities - a review. J Funct Foods 5, 997-1012.

5. Lee SH, Chung I-M, Cha Y-S, et al. (2010) Millet consumption decreased serum concentration of triglyceride and C-reactive protein but not oxidative status in hyperlipidemic rats. Nutr Res 30, 290-296.

6. Truswell AS (2002) Cereal grains and coronary heart disease. Eur J Clin Nutr 56, 1-14.

7. Gupta N, Srivastava AK \& Pandey VN (2012) Biodiversity and nutraceutical quality of some Indian millets. Proc Natl Acad Sci India Sect B Biol Sci 82, 265-273.

8. Edge MS, Jones JM \& Marquart L (2005) A new life for whole grains. J Am Diet Assoc 105, 1856-1860.

9. Mani UV, Prabhu BM, Damle SS, et al. (1993) Glycaemic index of some commonly consumed foods in western India. Asia Pac J Clin Nutr 2, 111-114.

10. Chethan S \& Malleshi N (2007) Finger millet polyphenols: optimization of extraction and the effect of $\mathrm{pH}$ on their stability. Food Chem 105, 862-870.

11. Chandrashekar A (2014) Chapter 6 - finger millet: Eleusine coracana. In Advances in Food and Nutrition Research [Internet] (cited 23 February 2014), pp. 215-262 [and Steve L. Taylor, editor]. San Diego, CA: Academic Press.

12. Sripriya G, Chandrasekharan K, Murty VS, et al. (1996) ESR spectroscopic studies on free radical quenching action of finger millet (Eleusine coracana). Food Chem 57, 537-540.

13. Shobana S, Sreerama YN \& Malleshi NG (2009) Composition and enzyme inhibitory properties of finger millet (Eleusine coracana L.) seed coat phenolics: mode of inhibition of $\alpha$-glucosidase and pancreatic amylase. Food Chem 115 , 1268-1273.

14. Hegde PS, Chandrakasan G \& Chandra TS (2002) Inhibition of collagen glycation and crosslinking in vitro by methanolic extracts of Finger millet (Eleusine coracana) and Kodo millet (Paspalum scrobiculatum). J Nutr Biochem 13, 517-521.

15. Kumari PL \& Sumathi S (2002) Effect of consumption of finger millet on hyperglycemia in non-insulin dependent diabetes mellitus (NIDDM) subjects. Plant Foods Hum Nutr 57, 205-213.

16. Hegde PS, Rajasekaran NS \& Chandra TS (2005) Effects of the antioxidant properties of millet species on oxidative stress and glycemic status in alloxan-induced rats. Nutr Res 25, 1109-1120.

17. Rajasekaran NS, Nithya M, Rose C, et al. (2004) The effect of finger millet feeding on the early responses during the process of wound healing in diabetic rats. Biochim Biophys Acta 1689, 190-201.

18. Shobana S, Harsha MR, Platel K, et al. (2010) Amelioration of hyperglycaemia and its associated complications by finger millet (Eleusine coracana L.) seed coat matter in streptozotocin-induced diabetic rats. Br J Nutr 104, 1787-1795.

19. Kannan S (2010) Finger millet in nutrition transition: an infant weaning food ingredient with chronic disease preventive potential. BrJ Nutr 104, 1733-1734.

20. Saucier G, Nadeau G, Brunet J, et al. (1963) Clinical use of the glucose disappearance rate. Can Med Assoc J 88, 1231-1237.

21. Singh DP \& Chopra K (2013) Verapamil augments the neuroprotectant action of berberine in rat model of transient global cerebral ischemia. Eur J Pharmacol 720, 98-106.

22. Devi PB, Vijayabharathi R, Sathyabama S, et al. (2014) Health benefits of finger millet (Eleusine coracana L.) polyphenols and dietary fiber: a review. J Food Sci Technol 51, 1021-1040.

23. Mangala SL, Malleshi NG, Tharanathan RN, et al. (1999) Resistant starch from differently processed rice and ragi (finger millet). Eur Food Res Technol 209, 32-37.

24. Pore MS \& Magar NG (1976) Effect of ragi feeding on serum cholesterol level. Indian J Med Res 64, 909-914.

25. Fernández-Sánchez A, Madrigal-Santillán E, Bautista M, et al. (2011) Inflammation, oxidative stress, and obesity. Int J Mol Sci 12, 3117-3132.

26. Chethan S, Dharmesh SM \& Malleshi NG (2008) Inhibition of aldose reductase from cataracted eye lenses by finger millet (Eleusine coracana) polyphenols. Bioorg Med Chem 16, 10085-10090.

27. Frederich RC, Hamann A, Anderson S, et al. (1995) Leptin levels reflect body lipid content in mice: evidence for dietinduced resistance to leptin action. Nat Med 1, 1311-1314.

28. Nov O, Shapiro H, Ovadia $H$, et al. (2013) Interleukin-1 $\beta$ regulates fat-liver crosstalk in obesity by auto-paracrine modulation of adipose tissue inflammation and expandability. PLOS ONE $\mathbf{8}$, e53626.

29. Hotamisligil GS, Shargill NS \& Spiegelman BM (1993) Adipose expression of tumor necrosis factor-alpha: direct role in obesity-linked insulin resistance. Science 259, 87-91.

30. Perreault M \& Marette A (2001) Targeted disruption of inducible nitric oxide synthase protects against obesitylinked insulin resistance in muscle. Nat Med 7, 1138-1143.

31. Fried SK, Bunkin DA \& Greenberg AS (1998) Omental and subcutaneous adipose tissues of obese subjects release interleukin-6: depot difference and regulation by glucocorticoid. J Clin Endocrinol Metab 83, 847-850.

32. Kanda H (2006) MCP-1 contributes to macrophage infiltration into adipose tissue, insulin resistance, and hepatic steatosis in obesity. J Clin Invest 116, 1494-1505.

33. Kamei N, Tobe K, Suzuki R, et al. (2006) Overexpression of monocyte chemoattractant protein-1 in adipose tissues causes macrophage recruitment and insulin resistance. J Biol Chem 281, 26602-26614.

34. Zhang HH, Halbleib M, Ahmad F, et al. (2002) Tumor necrosis factor-alpha stimulates lipolysis in differentiated human adipocytes through activation of extracellular signal-related kinase and elevation of intracellular cAMP. Diabetes 51, 2929-2935.

35. Nonogaki K, Fuller GM, Fuentes NL, et al. (1995) Interleukin-6 stimulates hepatic triglyceride secretion in rats. Endocrinology 136, 2143-2149.

36. Uysal KT, Wiesbrock SM, Marino MW, et al. (1997) Protection from obesity-induced insulin resistance in mice lacking TNF-alpha function. Nature 389, 610-614. 
37. Bahar B, O'Doherty JV \& Sweeney T (2011) A potential role of IL- 6 in the chito-oligosaccharide-mediated inhibition of adipogenesis. Br J Nutr 106, 1142-1153.

38. Smas CM \& Sul HS (1993) Pref-1, a protein containing EGF-like repeats, inhibits adipocyte differentiation. Cell $\mathbf{7 3}$, $725-734$

39. Wang Y \& Sul HS (2009) Pref-1 regulates mesenchymal cell commitment and differentiation through Sox9. Cell Metab 9, 287-302.

40. Kern PA, Di Gregorio G, Lu T, et al. (2004) Perilipin expression in human adipose tissue is elevated with obesity. J Clin Endocrinol Metab 89, 1352-1358.

41. Sawada T, Miyoshi H, Shimada K, et al. (2010) Perilipin overexpression in white adipose tissue induces a brown fat-like phenotype. PLOS ONE 5, e14006.

42. Berger J, Biswas C, Vicario PP, et al. (1989) Decreased expression of the insulin-responsive glucose transporter in diabetes and fasting. Nature 340, 70-72.

43. Garvey WT, Huecksteadt TP \& Birnbaum MJ (1989) Pretranslational suppression of an insulin-responsive glucose transporter in rats with diabetes mellitus. Science 245, 60-63.

44. Minokoshi Y, Kahn CR \& Kahn BB (2003) Tissue-specific ablation of the GLUT4 glucose transporter or the insulin receptor challenges assumptions about insulin action and glucose homeostasis. J Biol Chem 278, 33609-33612.

45. Ravussin E \& Smith SR (2002) Increased fat intake, impaired fat oxidation, and failure of fat cell proliferation result in ectopic fat storage, insulin resistance, and type 2 diabetes mellitus. Ann N Y Acad Sci 967, 363-378.
46. Delzenne NM \& Cani PD (2011) Interaction between obesity and the gut microbiota: relevance in nutrition. Annu Rev Nutr 31, 15-31.

47. Turnbaugh PJ, Bäckhed F, Fulton L, et al. (2008) Dietinduced obesity is linked to marked but reversible alterations in the mouse distal gut microbiome. Cell Host Microbe 3, 213-223.

48. Ouchi N, Parker JL, Lugus JJ, et al. (2011) Adipokines in inflammation and metabolic disease. Nat Rev Immunol 11, 85-97.

49. Cani PD, Amar J, Iglesias MA, et al. (2007) Metabolic endotoxemia initiates obesity and insulin resistance. Diabetes 56, 1761-1772

50. Fei N \& Zhao L (2013) An opportunistic pathogen isolated from the gut of an obese human causes obesity in germfree mice. ISME J 7, 880-884.

51. Neyrinck AM, Possemiers S, Druart C, et al. (2011) Prebiotic effects of wheat arabinoxylan related to the increase in Bifidobacteria, Roseburia and Bacteroides/Prevotella in diet-induced obese mice. PLOS ONE 6, e20944.

52. Flint HJ (2012) The impact of nutrition on the human microbiome. Nutr Rev 70, S10-S13.

53. Gao Z, Yin J, Zhang J, et al. (2009) Butyrate improves insulin sensitivity and increases energy expenditure in mice. Diabetes 58, 1509-1517.

54. Benjamin S \& Spener F (2009) Conjugated linoleic acids as functional food: an insight into their health benefits. Nutr Metab 6, 36. 